\title{
The impact of serological features in Chinese children with primary or past Epstein-Barr virus infections
}

\author{
Yuan Huang ${ }^{1,2}$, Cong Wei ${ }^{1}$, Kun Zheng ${ }^{1}$ and Dongchi Zhao ${ }^{1 *}$
}

\begin{abstract}
Background: Epstein-Barr virus (EBV) is a primary cause of infectious mononucleosis (IM) throughout the world, and the positive serology rate changes over time in infected individuals. The aim of this study was to explore the serological and clinical features among Chinese children with EBV infections. A retrospective study of children suspected of having IM was conducted. Peripheral blood samples were analyzed by indirect immunofluorescence to detect any EBV-specific antibodies. Samples were classed as positive $(+)$ or negative $(-)$ to immunoglobulins $M$ ( $\mathrm{IgM})$ or $\mathrm{G}(\mathrm{lgG})$ to the viral capsid antigen (VCA) or EBV nuclear antigen (EBNA). A standard medical history was taken, including epidemiological data and noting any clinical manifestations.

Results: Of 317 children, 37 were aged $<8$ months; 10 of these were VCA-IgM+, and the youngest was aged 1 month; 280 were aged $>8$ months. The EBV infection rate ranged from $21.4 \%$ among subjects aged $8-12$ months to $84.2 \%$ in those aged $>9$ years. Serologically, children who tested as VCA-lgM+ together with VCA-IgG and EBNAIgG- had longer hospital stays with more palatal petechiae and lymphadenopathy, especially among those with an atypical lymphocyte count of $>10 \%$. Children with the serological patterns [VCA-lgM-, VCA-lgG+ and EBNA-lgG-] and [VCA-lgM+ VCA-lgG+ and EBNA-lgG+] did not show specific clinical features.
\end{abstract}

Conclusions: Infants aged $<8$ months could be infected with EBV. About $84 \%$ of these Chinese children aged $>9$ years had serological evidence of EBV infection, whereas IM peaked in patients aged 2-3 years.

Keywords: Epstein-Barr virus, Children, Primary or post infection

\section{Background}

Epstein-Barr virus (EBV), a member of the herpesvirus family, is one of the primary causes of infectious mononucleosis (IM) in children and teenagers, and is widespread throughout the world. Following primary infection, the virus establishes lifelong latency, and more than $90 \%$ of adults today have serological evidence of past infections [1,2].

The indirect immunofluorescence assay (IFA) is widely used for the routine evaluation of EBV immunological status [3-5]. Although the EBV genome encodes many structural and nonstructural genes, those of most importance for serodiagnosis are the genes encoding the viral capsid antigens (VCAs), the early antigens (EAs) and the virus

\footnotetext{
* Correspondence: zhaodong@public.wh.hb.cn

'Pediatrics Department, Zhongnan Hospital, Wuhan University, Wuhan 430071, China

Full list of author information is available at the end of the article
}

nuclear antigens (EBNAs). Four serological parameters are essential for detecting EBV-specific immunoglobulin $M$ (IgM) or immunoglobulin G (IgG) antibodies in immunocompetent individuals on a qualitative basis: IgM-VCA, VCA-IgG, EA-IgG and EBNA-IgG. VCA-IgM is generally designated as an indicator of a recent primary infection [2]. Nevertheless, VCA-IgM might appear later, or might be produced only transiently, or might persist at such a low concentration as to be missed by laboratory tests and the low and high affinity IgG have different significance during EBV infection, low affinity anti-VCA IgG suggests a early stage infection and high anti-VCA IgG suggests post infection[6]. In addition, some patients do not produce EBNA-1-IgG [7], and even if this antibody is generated, it can disappear, especially among patients with immunosuppression $[8,9]$. Therefore, the routine addition of an estimation of anti-VCA-IgG avidity to diagnostic
C Biomed Central

(c) 2013 Huang et al.; licensee BioMed Central Ltd. This is an Open Access article distributed under the terms of the Creative Commons Attribution License (http://creativecommons.org/licenses/by/2.0), which permits unrestricted use, distribution, and reproduction in any medium, provided the original work is properly cited. 
EBV serology is recommended, and the combination of EBNA-IgG- and low-avidity VCA-IgG+ has excellent sensitivity and specificity $[4,10]$.

EBV seropositivity among children has much geographic variation. The positive rate is much higher among children in Asia than those in Western countries [11-14]. This study aimed to explore serological outcomes and clinical features in children with EBV infection and to interpret the implications.

\section{Methods}

A total of 317 inpatients (197 boys and 120 girls), with ages ranging from 1 to 164 months, were enrolled for this retrospective study. All were admitted to Zhongnan Hospital of Wuhan University, P. R. China, between July 2008 and August 2010, suspected of having IM. They had one of the following signs: (1) at least three of the EBV-related symptoms of fever, rash, lymphadenopathy, pharyngitis, palatal petechiae, hepatomegaly, or splenomegaly; (2) fever lasting longer than five days; (3) respiratory tract infection symptoms lasting longer than five days and unresponsive to conventional antibiotic treatment. Children with EBV-associated malignant diseases such as malignant lymphoma or chronic active EBV infection were excluded.

Informed consent was obtained from each patient parent at the time that serum samples were collected for assessing EBV antibody status. The study was approved by the Ethics Committee of Wuhan University Zhongnan Hospital, in accordance with the Helsinki Declaration.

\section{Definition of EBV infection}

A primary infection was defined as the presence of VCAIgM, or positive assays for EA-IgG or low-affinity antiVCA-IgG. Past infection was defined as a positive assay for IgG to VCA and IgG to EBNA, or the detection of highaffinity anti-VCA-IgG without VCA-IgM or EA-IgG.
Uninfected children were defined as having no detectable antibodies to EBV. Peripheral blood samples were obtained from all children within $24 \mathrm{~h}$ after admission to the pediatric department. Specific antibodies to EBV were detected using a commercial indirect immunofluorescence (IIF) kit IFA (EUROIMMUN, Lübeck, Germany) following the manufacturer's instructions $[10,15,16]$. The diagnosis of IM based on Sumaya criteria [17].

\section{Statistical analysis}

Data are presented as the percentage or mean \pm standard deviation (SD). All statistical analyses were performed using SPSS software (version 16; SPSS Inc., Chicago, IL, USA). The chi-squared test was used to compare between-group differences in percentages. The rank-sum test was used to compare differences between the dates of measurements, and $\mathrm{P}<0.05$ was accepted as statistically significant.

\section{Results}

\section{Serological features of EBV antibodies}

Of 317 patients, 37 children were aged $<8$ months: 27 boys and 10 girls. The EBV antibody patterns are shown in Table 1. The serological pattern [VCA-IgM-, VCAIgG and EBNA-IgG+] was the most common combination. Three patients aged 5, 6 and 7 months had the pattern [VCA-IgM+, VCA-IgG and EBNA-IgG-]. The youngest child with a primary infection was only 1 month old. There were 280 children aged $\geq 8$ months: 170 boys and 110 girls. The seropositive patterns included $95(33.9 \%)$ with a past infection, 60 (21.4\%) with a primary infection and $9(3.2 \%)$ with orphaned VCA-IgG+ (Table 2).

The distribution of antibodies by age is presented in Figure 1. The trends in the age distribution of VCA-IgG and EBNA-IgG antibodies were similar. The detection rates were the lowest among children aged 8-24 months

Table 1 EBV antibody combinations in EBV-positive patients aged <8 months $(n=37)$

\begin{tabular}{|c|c|c|c|c|c|c|c|}
\hline VCA-IgM & Low affinity & VCA-IgG & EBNA-IgG & EA-IgG & $\mathrm{n}$ & Percentage (\%) & Infection status \\
\hline+ & - & - & - & - & 3 & 8.1 & Primary infection \\
\hline+ & - & - & + & - & 2 & 5.4 & Primary infection \\
\hline+ & + & - & + & - & 1 & 2.7 & Primary infection \\
\hline+ & + & + & + & + & 1 & 2.7 & Primary infection \\
\hline- & + & + & + & - & 1 & 2.7 & Primary infection \\
\hline- & + & + & - & + & 1 & 2.7 & Primary infection \\
\hline- & - & + & + & + & 1 & 2.7 & Past infection or maternal antibodies \\
\hline- & - & + & + & - & 10 & 27.0 & Past infection or maternal antibodies \\
\hline- & - & + & - & - & 1 & 2.7 & Past infection or maternal antibodies \\
\hline- & - & - & + & - & 2 & 5.4 & Past infection or maternal antibodies \\
\hline- & - & - & - & - & 14 & 37.8 & No infection \\
\hline
\end{tabular}


Table 2 EBV antibody combinations in EBV-positive patients aged $\geq 8$ months $(n=280)$

\begin{tabular}{|c|c|c|c|c|c|c|c|}
\hline VCA-IgM & Low affinity & EA-lgG & VCA-IgG & EBNA-IgG & $\mathrm{N}$ & Percentage (\%) & Infection status \\
\hline+ & - & - & - & - & 7 & 2.5 & Primary infection \\
\hline+ & - & - & + & + & 8 & 2.9 & Primary infection \\
\hline+ & - & - & + & - & 1 & 0.4 & Primary infection \\
\hline+ & - & - & - & + & 1 & 0.4 & Primary infection \\
\hline+ & - & + & - & - & 1 & 0.4 & Primary infection \\
\hline+ & - & + & - & + & 1 & 0.4 & Primary infection \\
\hline+ & + & - & - & - & 6 & 2.1 & Primary infection \\
\hline+ & + & + & - & - & 3 & 1.1 & Primary infection \\
\hline+ & + & + & + & - & 1 & 0.4 & Primary infection \\
\hline+ & + & - & + & - & 1 & 0.4 & Primary infection \\
\hline - & + & - & - & - & 1 & 0.4 & Primary infection \\
\hline- & + & - & + & - & 2 & 0.7 & Primary infection \\
\hline- & + & + & + & - & 1 & 0.4 & Primary infection \\
\hline- & - & + & - & - & 4 & 1.4 & Primary infection \\
\hline- & - & + & + & - & 1 & 0.4 & Primary infection \\
\hline- & - & + & + & + & 21 & 7.5 & Primary infection \\
\hline- & - & - & + & + & 91 & 32.5 & Past infection \\
\hline- & - & - & - & + & 4 & 1.4 & Past infection \\
\hline- & - & - & + & - & 9 & 3.2 & Orphaned VCA-IgG \\
\hline- & - & - & - & - & 116 & 41.4 & No infection \\
\hline
\end{tabular}

and increased gradually with age. The detection rates of VCA-IgG and EBNA-IgG reached $60.5 \%$ and $62.8 \%$, respectively, in children aged $\geq 7$ years. Patients aged 8-24 months had a lower detection rate of EBNA-IgG than the other four groups $(P<0.001)$. Compared with the age groups of $2-4$ years, $4-7$ years and $\geq 7$ years, the patients aged 8-24 months had the lowest detection rates for VCA-IgG $(P<0.001)$.

\section{EBV seropositivity rate by age}

The patients were classified into five age groups. The presence of at least one positive result for VCA-IgM, VCA-

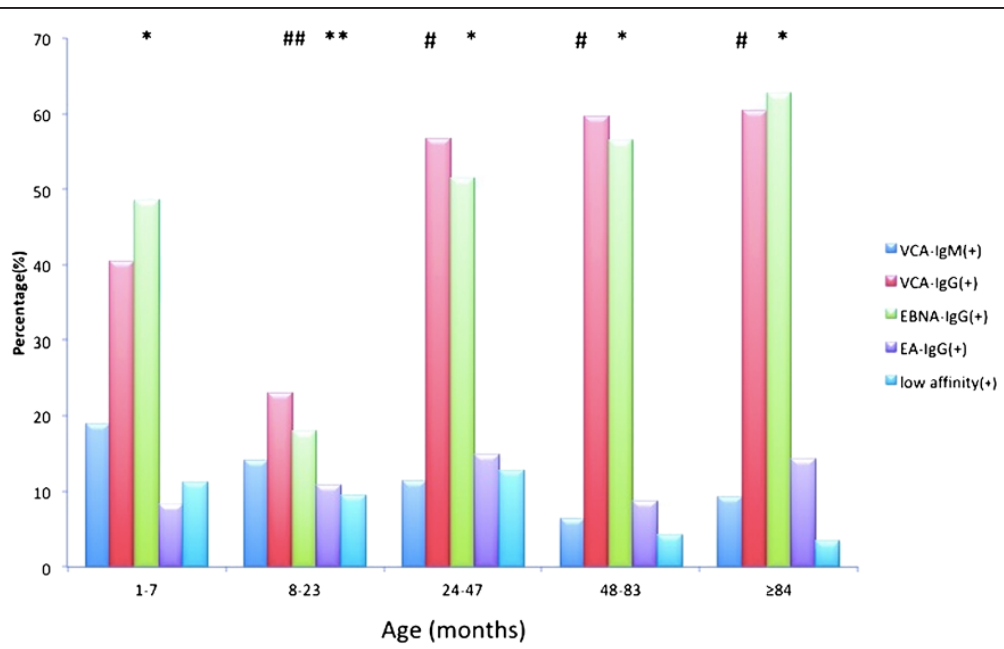

Figure 1 The distribution of antibodies in EBV-positive patients. $P<0.05$ between ${ }^{*}$ and ${ }^{* *}$, and between ${ }^{\#}$ and ${ }^{\# \#}$ 


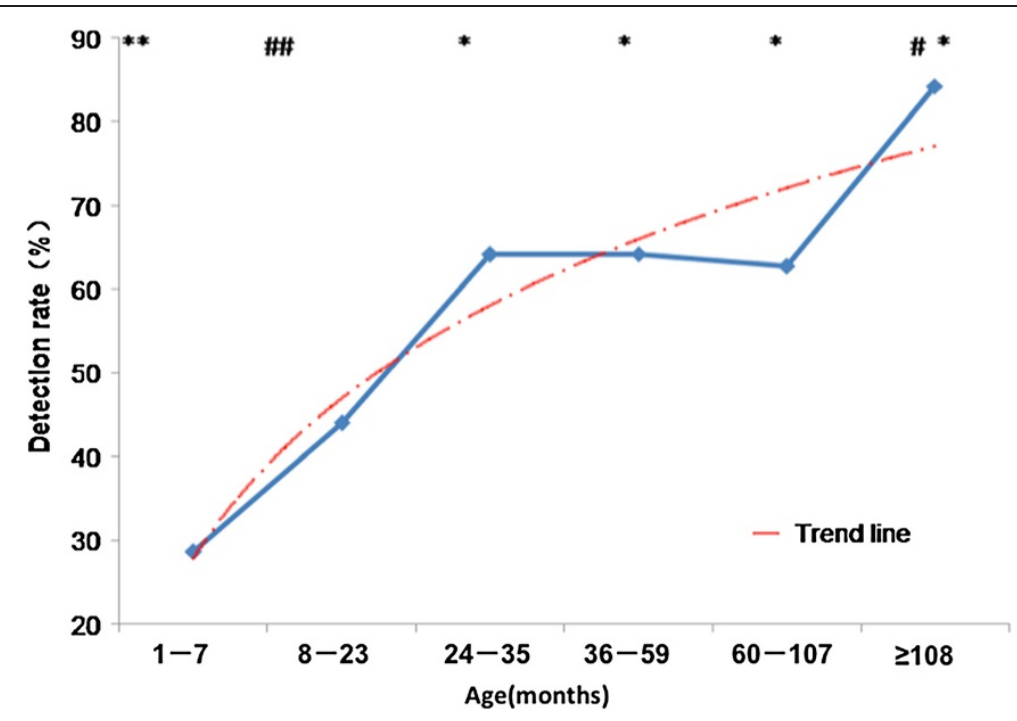

Figure 2 EBV infection rates by age. $P<0.05$ between ${ }^{*}$ and ${ }^{* *}$, and between ${ }^{*}$ and ${ }^{\# \#}$.

IgG or EBNA-IgG indicated that they had been infected with EBV. The seropositive rate increased among children aged 8-36 months and then plateaued among children aged $36-108$ months. For children aged $\geq 9$ years, the positive rate was $84.2 \%$ as shown in the trend line (Figure 2).
The disease spectrum of EBV infection

The EBV-related diseases were diverse (Table 3). The most common disease caused by a primary infection was respiratory tract infection (41.7\%), followed by IM (40.0\%), Kawasaki disease, anaphylactic purpura,

Table 3 The disease spectrum in EBV-positive children

\begin{tabular}{|c|c|c|c|c|}
\hline Diagnosis & $\begin{array}{l}\text { Primary infection } \\
(n=60)\end{array}$ & $\begin{array}{l}\text { Past infection } \\
(\mathrm{n}=95)\end{array}$ & $\begin{array}{l}\text { Orphaned VCA-IgG } \\
(\mathrm{n}=9)\end{array}$ & $\begin{array}{l}\text { No infection } \\
(n=116)\end{array}$ \\
\hline $\mathrm{IM}$ & $24(40.0 \%)$ & $3(3.2 \%)$ & $1(14.3 \%)$ & $5(4.3 \%)$ \\
\hline Respiratory infection & $25(41.7 \%)$ & $74(77.9 \%)$ & $7(77.8 \%)$ & $94(81.0 \%)$ \\
\hline Kawasaki disease & $2(3.3 \%)$ & $6(6.3 \%)$ & & $7(6.0 \%)$ \\
\hline ITP & $1(1.7 \%)$ & $1(1.1 \%)$ & & \\
\hline Anaphylactic purpura & $1(1.7 \%)$ & $1(1.1 \%)$ & & \\
\hline Ulcerative stomatitis & $1(1.7 \%)$ & & & \\
\hline Measles & $1(1.7 \%)$ & & & $1(0.9 \%)$ \\
\hline Asthma & $1(1.7 \%)$ & $2(2.1 \%)$ & & $3(2.6 \%)$ \\
\hline JRA & $1(1.7 \%)$ & $1(1.1 \%)$ & & \\
\hline Pulmonary tuberculosis & $1(1.7 \%)$ & $1(1.1 \%)$ & & \\
\hline Herpangina & $1(1.7 \%)$ & $1(1.1 \%)$ & & $2(1.7 \%)$ \\
\hline Hand-foot-mouth disease & $1(1.7 \%)$ & & & \\
\hline Summer fever & & $1(1.1 \%)$ & $1(14.3 \%)$ & \\
\hline GERD & & $1(1.1 \%)$ & & \\
\hline CMV infection & & $1(1.1 \%)$ & & \\
\hline Virus infection & & $1(1.1 \%)$ & & $1(0.9 \%)$ \\
\hline Fever of unknown origin & & $1(1.1 \%)$ & & \\
\hline Exanthema subitum & & & & $1(0.9 \%)$ \\
\hline Adenolymphitis & & & & $1(0.9 \%)$ \\
\hline Blood poisoning & & & & $1(0.9 \%)$ \\
\hline
\end{tabular}

IM, infectious mononucleosis; ITP, idiopathic thrombocytopenic purpura; JRA, juvenile rheumatoid arthritis; GERD, gastroesophageal reflux disease. 
Table 4 The distribution of age in EBV-positive patients (age $\geq 8$ months)

\begin{tabular}{llllll}
\hline Infection status & Age (months) & & & \\
\cline { 2 - 6 } & $\mathbf{8 - 1 1}$ & $\mathbf{1 2 - 2 3}$ & $\mathbf{2 4 - 3 5}$ & $\mathbf{3 6 - 5 9}$ & $\geq \mathbf{6 0}$ \\
\hline Primary infection $(\mathrm{n}=60)$ & $6(21.4 \%)$ & $13(26.0 \%)$ & $13(24.5 \%)$ & $13(18.6 \%)$ & $15(19.0 \%)$ \\
Past infection $(\mathrm{n}=95)$ & $1(3.6 \%)^{* *}$ & $7(14.0 \%)^{\# \#}$ & $19(35.9 \%)^{*}$ & $31(44.3 \%)^{* \#}$ & $37(46.8 \%)^{* *}$ \\
Orphaned VCA-lgG $(\mathrm{n}=9)$ & $1(3.6 \%)$ & $2(4.0 \%)$ & $2(3.8 \%)$ & $2(2.9 \%)$ & $2(2.5 \%)$ \\
No infection $(\mathrm{n}=116)$ & $20(71.4 \%)^{* *}$ & $28(56.0 \%)$ & $19(35.9 \%)^{*}$ & $24(34.3 \%)^{*}$ & $25(31.7 \%)^{*}$ \\
Total & 28 & 50 & 53 & 70 & 79 \\
\hline
\end{tabular}

$P<0.05$ between * and ${ }^{*}$, and between ${ }^{*}$ and ${ }^{\# \#}$.

idiopathic thrombocytopenic purpura, measles and asthma. Seven of the nine patients presenting with orphaned VCA-IgG were diagnosed with a respiratory tract infection.

\section{EBV primary/past infections and clinical features}

To analyze the clinical features of EBV infection by age, patients aged $\geq 8$ months were classified into four groups: 60 had a primary EBV infection, 95 had a past infection, nine had orphaned VCA-IgG and 116 were uninfected. The distribution in these four groups by age is shown in Table 4 . The age group of 1-2 years had the highest detection rate for a primary EBV infection. The incidence of past infection increased gradually with age from $3.6 \%$ to $46.8 \%$, and the patients aged 8-12 months had a lower incidence than the other three groups $(P<0.001)$ [Table 5]. These results indicate that EBV primary infection could be detected in all age groups.

There were no differences between these age groups in clinical features, but the mean hospital stay in the primary-infected group was longer than in the pastinfected group $(P<0.001)$. The age distribution of children with a primary EBV infection is shown in Table 6. The detection rate of IM was highest among children aged $2-3$ years. The clinical features in patients with a primary EBV infection divided into those with and without IM are listed in Table 7. Compared with the non-IM group, the IM group with a primary EBV infection had more frequent presentations of lymphadenopathy, pharyngitis, palatal petechiae, abnormal chest $\mathrm{X}$ rays, hepatomegaly and splenomegaly, an atypical lymphocyte count $>10 \%$ and abnormal liver function. Patients without IM were classified into three groups: 36 had a primary HBV infection, 92

Table 5 The distribution of EBV primary-infected patients by age

\begin{tabular}{llll}
\hline $\begin{array}{l}\text { Primary infection } \\
(\mathbf{n}=\mathbf{6 9})\end{array}$ & \multicolumn{3}{c}{ Age (months) } \\
\cline { 2 - 4 } & $\mathbf{1 - 2 3}$ & $\mathbf{2 4 - 3 5}$ & $\geq \mathbf{3 6}$ \\
\hline $\mathrm{IM}(\mathrm{n}=24)$ & $7(25.0 \%)$ & $7(53.9 \%)$ & $10(35.7 \%)$ \\
Non-IM $(\mathrm{n}=45)$ & $21(75.0 \%)$ & $6(46.1 \%)$ & $18(64.3 \%)$ \\
Total & 28 & 13 & 28 \\
\hline
\end{tabular}

had a past infection and 111 were uninfected (Table 7). Rash was more frequent in children with a primary HBV infection than in the other two groups $(P<0.01)$, but they had a lower rate of abnormal chest $\mathrm{X}$ rays $(P<0.001)$.

\section{Clinical features of different antibody combinations}

To understand the implication of different antibody combinations, five patterns were compared: group A [VCA-IgM+, VCA-IgG- and EBNA-IgG-]; group B [VCA-IgM+, VCA-IgG+ and EBNA-IgG+]; group C [VCA-IgM-, VCA-IgG+ and EBNA-IgG-]; group D [VCA-IgM-, VCA-IgG+ and EBNA-IgG+]; and group E [VCA-IgM-, VCA-IgG- and EBNA-IgG-]. The symptoms and physical signs seemed to be most severe in the patients of group A, especially an atypical lymphocyte

Table 6 Features in patients with an EBV primary infection

\begin{tabular}{|c|c|c|}
\hline \multirow[t]{2}{*}{ Clinical features } & \multicolumn{2}{|c|}{ Primary infection } \\
\hline & $\mathrm{IM}(\mathrm{n}=24)$ & Non-IM $(n=36)$ \\
\hline Age (months) & $47.8 \pm 38.8$ & $41.8 \pm 32.3$ \\
\hline Male/female patients & $11 / 13$ & $17 / 19$ \\
\hline Length of stay (days) & $11.0 \pm 2.7^{*}$ & $9.1 \pm 4.1$ \\
\hline Fever & $23(95.8 \%)$ & $31(86.1 \%)$ \\
\hline Cough & $12(50.0 \%)^{*}$ & 30 (83.3\%) \\
\hline Rash & $4(16.7 \%)$ & 14 (38.9\%) \\
\hline Lymphadenopathy & $20(83.3 \%)^{*}$ & $11(30.6 \%)$ \\
\hline Pharyngitis & $23(95.8 \%)^{*}$ & $26(72.2 \%)$ \\
\hline Palatal petechiae & $13(54.2 \%)^{*}$ & $3(8.3 \%)$ \\
\hline Abnormal chest $X$ ray & $6 / 7(85.7 \%)^{*}$ & $7 / 20(35.0 \%)$ \\
\hline Hepatomegaly & $11(45.8 \%)^{*}$ & $0(0.0 \%)$ \\
\hline Splenomegaly & $8(33.3 \%)^{*}$ & $0(0.0 \%)$ \\
\hline$A L C>10 \%$ & $17 / 23(73.9 \%)^{*}$ & $3 / 21(14.3 \%)$ \\
\hline Elevated ESR & $11 / 20(55.0 \%)$ & $10 / 21(47.6 \%)$ \\
\hline Elevated CRP & $9 / 19(47.4 \%)$ & $10 / 21(47.6 \%)$ \\
\hline ALF & $13 / 18(72.2 \%)^{*}$ & $4 / 18(22.2 \%)$ \\
\hline
\end{tabular}

IM, infectious mononucleosis; Non-IM, patients without IM; ALC, atypical lymphocytes; ESR, erythrocyte sedimentation rate; CRP, C-reactive protein; ALF, abnormal liver function (alanine aminotransferase or aspartate aminotransferase levels $>46 \mathrm{U} / \mathrm{L}$ ). ${ }^{*} P<0.05$ versus the non-IM group. 
Table 7 Features in patients not diagnosed with IM

\begin{tabular}{llll}
\hline Clinical features & Primary infection(n= 36) & Past infection(n= 92) & No infection(n = 111) \\
\hline Age (months) & $41.8 \pm 32.3^{*}$ & $60.3 \pm 37.7^{* *}$ & $37.7 \pm 29.5^{*}$ \\
Male/female patients & $17 / 19$ & $57 / 35$ & $74 / 37$ \\
Length of stay (days) & $9.1 \pm 4.1$ & $7.8 \pm 2.5^{*}$ & $8.9 \pm 3.9$ \\
Fever & $31(86.1 \%)$ & $83(90.2 \%)$ & $97(87.4 \%)$ \\
Cough & $30(83.3 \%)$ & $65(70.6 \%)$ & $85(76.6 \%)$ \\
Rash & $14(38.9 \%)^{* *}$ & $17(18.5 \%)^{*}$ & $16(14.4 \%)^{*}$ \\
Lymphadenopathy & $11(30.6 \%)$ & $33(35.9 \%)$ & $29(1.8 \%)^{*}$ \\
Pharyngitis & $26(72.2 \%)$ & $74(80.4 \%)$ & $79(71.2 \%)$ \\
Palatal petechiae & $3(8.3 \%)$ & $16(17.4)$ & $20(18.0 \%)$ \\
Abnormal chest X ray & $7 / 20(35.0 \%)^{* *}$ & $40 / 46(87.0 \%)^{*}$ & $49 / 61(80.3 \%)^{*}$ \\
Hepatomegaly & & $5(5.4 \%)$ & $7(6.3 \%)$ \\
Splenomegaly & $0(0.0 \%)$ & $3(3.3 \%)$ & $1(0.9 \%)$ \\
ALC $>10 \%$ & $3 / 21(14.3 \%)$ & $9 / 51(17.7 \%)$ & $13 / 70(18.6 \%)$ \\
Elevated ESR & $10 / 21(47.6 \%)$ & $35 / 67(53.2 \%)$ & $30 / 63(47.6 \%)$ \\
Elevated CRP & $10 / 21(47.6 \%)$ & $33 / 68(48.5 \%)$ & $42 / 73(57.5 \%)$ \\
ALF & $4 / 18(22.2 \%)$ & $3 / 24(12.5 \%)$ & $12 / 33(36.4 \%)$ \\
\hline
\end{tabular}

IM, infectious mononucleosis; Non-IM, patients without IM; ALC, atypical lymphocytes; ESR, erythrocyte sedimentation rate; CRP, C-reactive protein; ALF abnormal liver function (alanine aminotransferase or aspartate aminotransferase levels $>46 \mathrm{U} / \mathrm{L}$ ). $P<0.05$ between ${ }^{*}$ and ${ }^{* *}$.

count of $>10 \%$. The symptoms, physical signs and laboratory results in groups $\mathrm{B}$ and $\mathrm{C}$ were not more serious than in groups $\mathrm{D}$ or $\mathrm{E}$. The pattern of group $\mathrm{C}$ [VCA-IgM-, VCA-IgG+ and EBNA-IgG-] did not have any specific clinical features (Table 8).

\section{Discussion}

We found that EBV was a common pathogen in these Chinese children with respiratory tract infections and that those aged 8-36 months had the highest risk of a primary EBV infection. The determination of immunoglobulins

Table 8 Clinical features of different antibody combinations in EBV-positive patients (age $\geq \mathbf{8}$ months)

\begin{tabular}{|c|c|c|c|c|c|}
\hline Clinical features & $A(n=17)$ & $B(n=8)$ & $C(n=13)$ & $D(n=112)$ & $E(n=121)$ \\
\hline Length of stay (days) & $10.5 \pm 2.9^{*}$ & $10.4 \pm 4.9$ & $9.0 \pm 4.5$ & $8.0 \pm 2.9^{*}$ & $9.1 \pm 4.0$ \\
\hline Fever & $17(100.0 \%)$ & $8(100.0 \%)$ & $12(92.3 \%)$ & $100(89.3 \%)$ & $106(87.6 \%)$ \\
\hline Cough & 9 (52.9\%) & $8(100.0 \%)$ & $12(92.3 \%)$ & 79 (70.5\%) & $90(74.4 \%)$ \\
\hline Rash & $4(23.5 \%)$ & $4(50.0 \%)$ & $0(0.0 \%)$ & $23(20.5 \%)$ & $19(15.7 \%)$ \\
\hline Lymphadenopathy & $11(64.7 \%)^{* *}$ & $6(75.0 \%)$ & $5(38.5 \%)$ & $41(36.6 \%)$ & $35(28.9 \%)^{*}$ \\
\hline Pharyngitis & $16(94.1 \%)$ & 7 (87.5\%) & $10(76.9 \%)$ & $89(79.5 \%)$ & 87 (71.9\%) \\
\hline Palatal petechiae & $9(52.9 \%)^{* *}$ & $2(25.0 \%)$ & $5(38.5 \%)$ & $20(17.9 \%)^{*}$ & $24(19.8 \%)$ \\
\hline Abnormal chest $X$ ray & 8/9 (88.9\%) & $2 / 2(100.0 \%)$ & $3 / 5(60.0 \%)$ & $50 / 57(87.7 \%)$ & $53 / 65(81.5 \%)$ \\
\hline Bronchitis ( $X$ ray) & 3/9 (33.3\%) & $1 / 2(50.0 \%)$ & $2 / 5(40.0 \%)$ & $32 / 57(56.1 \%)$ & 25/65 (38.5\%) \\
\hline Pneumonia ( $X$ ray) & $5 / 9(55.6 \%)$ & $1 / 2(50.0 \%)$ & $1 / 5(20.0 \%)$ & 18/57 (31.6\%) & $28 / 65$ (43.1\%) \\
\hline Hepatomegaly & $5(29.4 \%)$ & $2(25.0 \%)$ & $3(23.1 \%)$ & $7(6.3 \%)$ & $11(9.1 \%)$ \\
\hline Splenomegaly & $4(23.5 \%)$ & $0(0.0 \%)$ & $1(7.7 \%)$ & $7(6.3 \%)$ & $5(4.1 \%)$ \\
\hline $\mathrm{ALC}>10 \%$ & $12 / 15(80.0 \%)^{* *}$ & $0 / 6(0.0 \%)^{*}$ & $4 / 8(50.0 \%)$ & $14 / 66(21.2 \%)^{*}$ & $18 / 77(23.4 \%)^{*}$ \\
\hline Elevated ESR & 8/14 (57.1\%) & $5 / 6(83.3 \%)$ & $2 / 10(20.0 \%)$ & 43/81 (53.1\%) & $31 / 66(47.0 \%)$ \\
\hline Elevated CRP & 4/13 (30.8\%) & $5 / 6(83.3 \%)$ & $5 / 9(55.6 \%)$ & $42 / 83(50.6 \%)$ & $43 / 76(56.6 \%)$ \\
\hline ALF & 9/13 (69.2\%) & $1 / 4(25.0 \%)$ & $2 / 6(33.3 \%)$ & 9/36 (25.0\%) & $15 / 38$ (39.5\%) \\
\hline
\end{tabular}

A: patients with the antibody combination of [VCA-lgM+, VCA-lgG- and EBNA-lgG-]. B: patients with the antibody combination of [VCA-lgM+, VCA-lgG+ and EBNA-lgG+]. C: patients with the antibody combination of [VCA-lgM-, VCA-lgG+ and EBNA-lgG-]. D: patients with the antibody combination of [VCA-lgM-, VCAIgG+ and EBNA-lgG+]. E: patients with the antibody combination of [VCA-lgM-, VCA-lgG- and EBNA-lgG-]. ESR, erythrocyte sedimentation rate; CRP, C-reactive protein; ALC, atypical lymphocytes; ALF, abnormal liver function (alanine aminotransferase or aspartate aminotransferase levels $>46 \mathrm{U} / \mathrm{L}$ ). $P<0.05$ between * and ${ }^{* *}$. 
against specific antigens of EBV is recommended in pediatric patients $[15,17]$. VCA-IgM is generally designated as an indicator of recent primary infection. VCA and EBNA cause lifelong persistent IgG titers. The avidity of VCA-IgG antibodies detected is low in samples from patients with recent EBV infections and high in patients with a past infection or reactivation $[10,17]$. The combination of negative EBNA-IgG and low-avidity VCA-IgG has given a sensitivity and specificity of $100 \%$ [4].

In the present study, there were no differences between the age groups in the detection rates for VCA-IgM, EAIgG and low-affinity VCA-IgG. The detection rates were the lowest among those aged 8-24 months and increased gradually with age. These two antibodies are the most frequent in this age group because of the persistence of maternal antibodies in children aged $<8$ months; after the maternal antibodies disappear, the infection rate increases gradually. Most maternal antibodies disappear at 4 months of age and are no longer detectable at 8 months [11]. To exclude the impact of maternal antibodies, patients were divided into two groups, with 8 months as the cutoff. Five patients had the combination of VCA-IgM + with low-affinity VCA-IgG-, three of whom presented with a primary cytomegalovirus (CMV) infection. This is known to produce a false-positive result for VCA-IgM [18], so given the protective role played by maternal antibodies, we surmise that the positive result for VCA-IgM in these patients was induced by the CMV infection. The youngest infant with a primary EBV infection having the pattern of [VCA-IgM+, low affinity VCA-IgG+, EBNAIgG+, VCA-IgG- and EA-IgG-] was only 1 month old, and this was probably caused by an intrauterine or intrapartum infection. Previous studies have shown that EBV might be present in cervical secretions, and EBV seems to be able to cross the placenta and to cause placental infections manifested by deciduitis and villitis [19].

The presence of VCA-IgG in the absence of VCA-IgM and EBNA-IgG antibodies makes classifying EBV infection more difficult. This serological picture can be seen in cases of past infection with EBNA-IgG showing loss or nonappearance of these antibodies, or in patients with primary EBV infections with the early disappearance or delayed onset of production of VCA-IgM. In this series, 13 patients $(4.64 \%)$ were diagnosed with orphan VCAIgG+. A study in 2009 found that the prevalence of the [VCA-IgG+, VCA IgM- and EBNA-1-IgG-] serological combination in children aged $1-10$ years was $4.5 \%$, and it was associated mainly with acute infection [20,21]. In the present study, patients with this serological pattern seemed to have more severe symptoms, physical signs and adverse laboratory results, especially an atypical lymphocyte count of $>10 \%$ compared with the pattern [VCA-IgM-, VCA-IgG+ and EBNA-IgG-]. This could have been associated with an EBV primary infection causing IM. EBV-associated IM occurred in all age groups, with a peak incidence at 2-4 years in Hong Kong [22], which is similar to the result of our study (a peak incidence at 2-3 years).

The disease spectrum associated with a primary EBV infection is very diverse. In most studies published outside China, about $50 \%$ of children with an EBV infection develop IM [23], and the proportion of IM seen in our study was similar $(40 \%)$ and much higher than other studies in China $[24,25]$, where the proportion of IM in the disease spectrum was only $17.9 \%$. However, our results show that EBV mainly caused respiratory tract infections. These results suggest that EBV is a common pathogen in respiratory tract infections as well as in IM. EBV seropositivity among children has a geographic variation: the age of primary infection is earlier in Asia and other developing countries than in Western countries. The infection rate of 2-year-old children exceeded $60.7 \%$ in Hong Kong in 2001 [12]. In our study, the positive rate among children aged $2-3$ years was $64.5 \%$. However, it was $84.2 \%$ among those aged $\geq 9$ years, so there was no obvious decline in the infection rate.

\section{Conclusions}

These Chinese infants aged $<8$ months could be infected by EBV and about $84 \%$ of children aged $\geq 9$ years had serological evidence of EBV infection. In addition to causing IM, EBV was also a common pathogen in children with respiratory tract infections. The detection rate of EBV-related IM peaked in patients aged 2-3 years.

\section{Abbreviations}

EBV: Epstein-Barr virus; CMV: Cytomegalovirus; IM: Infectious mononucleosis; VCA: Viral capsid antigen; EA: Early antigen; EBNA: Epstein-Barr virus nuclear antigen; IFA: Indirect immunofluorescence assay; IgG: Immunoglobulin G; IgM: Immunoglobulin M.

\section{Competing interests}

The authors declare that they have no competing interests.

\section{Authors' contributions}

HY collected the data and wrote the manuscript. WC and ZK discussed and reviewed the manuscript. DZ designed the manuscript and analyzed the data. All authors read and approved the final manuscript.

\section{Acknowledgements}

This work was supported by China National Natural Science Foundation (No. 30973220).

\section{Author details}

'Pediatrics Department, Zhongnan Hospital, Wuhan University, Wuhan 430071, China. ${ }^{2}$ Pediatrics Department, Children's Hospital, Zhejiang

University School of Medicine, Hangzhou 310000, China.

Received: 29 February 2012 Accepted: 27 December 2012

Published: 13 February 2013

\section{References}

1. Nalesnik MA: Epstein-Barr Virus. In Laboratory Diagnosis of Viral Infections. Edited by Lennette EH, Smith TF. New York: Marcel Dekker, Inc; 1999:85-419. 
2. Odumade OA, Hogquist KA, Balfour HH Jr: Progress and problems in understanding and managing primary Epstein-Barr virus infections. Clin Microbiol Rev 2011, 24:193-209.

3. Gärtner B, Preiksaitis JK: EBV viral load detection in clinical virology. J Clin Virol 2010, 48:82-90.

4. Hess RD: Routine Epstein-Barr virus diagnostics from the laboratory perspective: still challenging after 35 years. J Clin Microbiol 2004, 42:3381-3387.

5. Rea TD, Ashley RL, Russo JE, Buchwald DS: A systematic study of EpsteinBarr virus serologic assays following acute infection. Am J Clin Pathol 2002, 117:156-161

6. Bauer G: The rational basis for efficient Epstein-Barr virus (EBV) serology. Clin Lab 1995, 41:623-634.

7. Kampmann M, Henninger K, Bauer G: Determination of antibodies directed specifically against Epstein-Barr virus nuclear antigen-1 (EBNA-1) by anticomplementary immunofluorescence (ACIF). Med Microbiol Lett 1993, 2:1-8,

8. Bauer G: Simplicity through complexity: immunoblot with recombinant antigens as the new gold standard in Epstein-Barr virus serology. Clin Lab 2001, 47:223-230.

9. Vetter $V$, Kreutzer $L$, Bauer $G$ : Differentiation of primary from secondary anti-EBNA-1-negative cases by determination of avidity of VCA-lgG. Clin Diagn Virol 1994, 2:29-39.

10. Robertson P, Beynon S, Whybin R, Brennan C, Vollmer-Conna U, Hickie I, Lloyd A: Measurement of EBV-lgG anti-VCA avidity aids the early and reliable diagnosis of primary EBV infection. J Med Virol 2003, 70:617-623.

11. Rickinson A, Kieff E: Epstein-Barr virus. In Fields Virology. 4th edition. Edited by Knipe D, Howley P. Philadelphia: Lippincott Williams \& Wilkins; 2001:2575-2627.

12. Chan KH, Tam JS, Peiris JS, Seto WH, Ng MH: Epstein-Barr virus (EBV) infection in infancy. J Clin Virol 2001, 21:57-62.

13. Kangro HO, Osman HK, Lau YL, Heath RB, Yeung CY, Ng MH: Seroprevalence of antibodies to human herpesviruses in England and Hong Kong. J Med Virol 1994, 43:91-96.

14. Takeuchi K, Tanaka-Taya K, Kazuyama Y, Ito YM, Hashimoto S, Fukayama M, Mori S: Prevalence of Epstein-Barr virus in Japan: trends and future prediction. Pathol Int 2006, 56:112-116.

15. Tamaro G, Donato M, Princi T, Parco S: Correlation between the immunological condition and the results of immunoenzymatic tests in diagnosing infectious mononucleosis. Acta Biomed 2009, 80:47-50.

16. Binnicker MJ, Jespersen DJ, Harring JA, Rollins LO, Beito EM: Evaluation of a multiplex flow immunoassay for detection of Epstein-Barr virus-specific antibodies. Clin Vaccine Immunol 2008, 15:1410-1413.

17. Dohno S, Maeda A, Ishiura Y, Sato T, Fujieda M, Wakiguchi H: Diagnosis of infectious mononucleosis caused by Epstein-Barr virus in infants. Pediatr Int 2010, 52:536-540.

18. Aalto SM, Linnavuori K, Peltola H, Vuori E, Weissbrich B, Schubert J, Hedman L, Hedman K: Immunoreactivation of Epstein-Barr virus due to cytomegalovirus primary infection. J Med Virol 1998, 56:186-191.

19. Avgil M, Ornoy A: Herpes simplex virus and Epstein-Barr virus infections in pregnancy: consequences of neonatal or intrauterine infection. Reprod Toxicol 2006, 21:436-445.

20. De Paschale M, Agrappi C, Manco MT, Mirri P, Viganò EF, Clerici P: Seroepidemiology of EBV and Interpretation of the "Isolated VCA IgG" pattern. J Med Virol 2009, 81:325-331.

21. Tone $W N$, Helge M: Prevalence of primary versus reactivated Epstein-Barr virus infection in patients with VCA IgG-, VCA IgM- and EBNA-1-antibodies and suspected infectious mononucleosis. J Clin/ Virol 2007, 38:292-297.

22. Chan CW, Chiang AK, Chan KH, Lau AS: Epstein-Barr virus associated Infectious mononucleosis in Chinese children. Pediatr Infect Dis J 2003, 22:974-978.

23. Macsween KF, Crawford DH: Epstein-Barr Virus-recent advances. Lancet Infect Dis 2003, 3:131-140.

24. Gao LW, Xie ZD, Liu YY, Wang Y, Shen KL: Epidemiologic and clinical characteristics of infectious mononucleosis associated with Epstein-Barr virus infection in children in Beijing. China. World J Pediatr 2011, 7:45-49

25. Wang $X$, Yang $K$, Wei $C$, Huang $Y$, Zhao D: Coinfection with EBV/CMV and other respiratory agents in children with suspected infectious mononucleosis. Virol J 2010, 7:247.

doi:10.1186/1743-422X-10-55

Cite this article as: Huang et al:: The impact of serological features in Chinese children with primary or past Epstein-Barr virus infections. Virology Journal 2013 10:55.

\section{Submit your next manuscript to BioMed Central and take full advantage of:}

- Convenient online submission

- Thorough peer review

- No space constraints or color figure charges

- Immediate publication on acceptance

- Inclusion in PubMed, CAS, Scopus and Google Scholar

- Research which is freely available for redistribution 